\title{
A STUDY OF CHEMICAL AND PHYSICAL CHANGES DURING BIAXIALLY ORIENTED POLYPROPYLENE FILM PRODUCTION
}

\author{
Semra (IIkü", Devrim Balköse. Esen Arkıs and Muzaffer Sipahioglu \\ Izmir Institute of Technologv \\ Faculty of Engineering. Department of ('hemical Engineering \\ Gülbahçeköyü Urla İmir Turkey
}

\begin{abstract}
Polypropylene films obtained during the biaxial orientation process were characterized by energy dispersive $\mathrm{X}$-ray analysis (EDX), scanning electron microscopy, X-ray diffraction, differential scanning calorimetry, infrared spectroscopy. Inorganic particles with $\mathrm{Al}, \mathrm{Si}, \mathrm{Na}, \mathrm{Mg}, \mathrm{Ti}, \mathrm{K} . \mathrm{O}$ elements were present in biaxially oriented films. Polypropylene had molecules with both isotactic configuration and it was crystallized only in isotactic $\alpha$ phase. The films drawn in one and two directions had unit cells with $b$ axis parallel to surface of the films. The antioxidants present in the films were consumed during processing, preventing polypropylene oxidation in air at high processing temperatures. One surface of the films contained less polypropylene and had functional groups rich in oxygen such as $\mathrm{C}=\mathrm{O}$ and COO:
\end{abstract}

Key words: polypropylene, crystallinity, melting endotherm. crystallization, biaxial orientation

"Correspondence to: Semra Ülkü, President of Izmir Institute of Technology, Gülbahçeköyü Urla Izmir Turkey Tel: +90 232 750600I; E-mail: semraulku@.iyte.edu.tr 


\section{INTRODUCTION}

Polypropylene films used in the packaging industry are produced by biaxial stretching either by blow molding or longitudinal and transverse stretching sequentially. The diverse possibility of the presence of different crystalline phases of polypropylene makes possible the production of films with different properties by regulating the process conditions. Multilayer films with better adhesion property at one surface can also be produced by this method.

\section{Crystal structure of polypropylene}

Polypropylene may be found in isotactic, syndiotactic and atactic molecular structures. Isotactic polypropylene may be crystallized as an $\alpha$ monoclinic structure with unit cell dimensions of $0.665,2.056$, and $0.65 \mathrm{~nm}$ having a unit cell angle of $99.3^{\circ}$. The $\alpha$ structure of polypropylene has reflection maxima at $2 \theta$ values $14.2^{\circ}, 17^{\circ}, 18.8^{\circ}, 21.2^{0}, 21.9^{\circ}$ for planes (110), (040), (130), (111) and (131) respectively /1,2/.

There are two variants in the $\alpha$ phase: the less stable $\alpha_{1}$ phase (space group $\mathrm{C} 2 / \mathrm{c}$ ) and the more stable $\alpha_{2}$ phase $\left(\mathrm{P} 2_{1} / \mathrm{c}\right)$. Both have a common arrangement of helical senses: on all the $(040)$ faces the winding direction of helices, left and right, is in alternate order. However, their methyl group arrangement is different. In the $\alpha_{2}$ phase it is perfectly ordered while it is random in the $\alpha_{1}$ phase. The usual isotactic polypropylene is a mixture of the $\alpha_{1}$ and $\alpha_{2}$ phases. Reorganization and recrystallization from $\alpha_{1}$ to phase $\alpha_{2}$ is known to occur with the fusion of the $\alpha_{1}$ phase. The peak at $2 \theta$ value $31.6^{\circ}$ belongs to diffraction from ( $\overline{2} 31$ ) and ( $\overline{161}$ ) planes of the $\alpha_{2}$ phase $/ 3 /$.

Polypropylene may also be crystallized in $\beta$ hexagonal structure with unit cell dimensions of 1.274 and $0.635 \mathrm{~nm}$ with reflection maxima at $2 \theta$ values of 16.1 and $21.1^{\circ}$. Syndiotactic polypropylene crystals are in orthorhombic structure with unit cell dimensions of $1.45,0.58$ and $0.74 \mathrm{~nm}$. The maximum reflection in the $\mathrm{X}$-ray diagram of syndiotactic polypropylene is at $2 \theta$ value of $16.2^{\circ}$ for $(300)$ planes $/ 4 /$.

\section{Melting behaviour of polypropylene}

Effects of tacticity and molecular weight on crystallinity and melting behaviour were studied by many authors. Paukkeri and Lehtinen found that in 
the molecular weight range of $22000-947000$ isotacticity was the main parameter in determining the temperature of crystallization, and glass transition temperature as well as the crystallization rate, but molecular weight had almost no influence on crystallinity. The shape of melting isotherms was clearly influenced by molecular weight in the low molecular weight region $15 /$.

The $\alpha$ structure of isotactic polypropylene melts at about $170^{\prime \prime} \mathrm{C}$ whereas the $\beta$ structure melts at about $140-150^{\circ} \mathrm{C}$. On quenching molten isotactic polypropylene from $200^{\circ} \mathrm{C}$ to $90^{\circ} \mathrm{C}$ rapidly, different crystal structures form according to the cooling rate.

If heating rate decreases then diffraction peaks for the $\alpha$ crystal structure become sharp peaks. If cooling rate is above $140^{\circ} \mathrm{C} / \mathrm{sec}$ and between $120^{\circ} \mathrm{C}$ and $78^{\circ} \mathrm{C} / \mathrm{sec}$, then mesomorphic structure and $\alpha$ structure have distinct peaks respectively; and at low rates such as $0.28^{\circ} \mathrm{C} / \mathrm{sec}, \alpha$ structure has sharp peaks.

\section{Relative proportions of the $\alpha$ and $\beta$ forms}

Relative proportions of the $\alpha$ and $\beta$ forms present in isotactic polypropylene samples can be measured by an empirical parameter, $k$, as

$$
k=\frac{I_{(300) \beta}}{\left(I_{(300) \beta}+\left(I_{(110) \alpha}+I_{(040) \alpha}+I_{(130) \alpha}\right)\right.}
$$

where $I_{(1 / 0)_{\alpha,}} I_{(1)+(1))_{a}}$ and $I_{(/ 3(1)) a}$ are the heights of the three strong equatorial $\alpha-$ form peaks $(110),(040)$, and $(130) . I_{(3(1)) f}$ is that of the strongest peak characteristic of $\beta$-form (300) /6/. It is used for WAXD analysis. It represents $\beta$ crystal content for the diffraction curves according to Turner-Jones et $a$. $17 /$. The $\mathrm{k}$ value is zero in the absence of the $\beta$-form and unity if only $\beta$-form is present $/ 8 / . \beta$-nucleator content, casting conditions and melt flow index of base polypropylene influence formation of $\beta$-crystals $/ 7$.

\section{Degree of crystallinity}

The degree of crystallinity of the $a$-form of polypropylene can be obtained as

$$
\mathrm{W}_{\mathrm{c.x}}=\frac{I_{c}}{l_{c}+1.25 I_{\mathrm{ix}}}
$$


where $\mathrm{W}_{\mathrm{c.x}}$ is the degree of crystallinity of $\alpha$-isotactic polypropylene, $I_{a}$ is the integral intensity of the amorphous peak and $I_{c}=I_{110}+1.63 I_{040}+2.14 I_{1301}$ $+3.51 I_{04} \bar{\uparrow}$ where $I_{1110}, I_{(104)}, I_{130)}$, and $I_{04} \bar{i}$ are the intensities of (110), (040), (130), and $(04 \overline{1})$ planes $/ 6 /$.

Temperature dependence of $\mathrm{X}$-ray diffraction profiles was studied by Naiki et al. 13/. The degree of crystallinity gradually decreased with increasing temperature up to $150^{\circ} \mathrm{C}$. This is due to the fact that the diffraction intensity is decreased by the thermal motion of the crystalline atoms, and the resulting thermal diffuse scattering was counted as amorphous scattering. In the region of $155-164^{\circ} \mathrm{C}$ the structural ordering is comparable with the decrease in the diffraction intensity by the thermal motion of the atoms. Above $160^{\circ} \mathrm{C}$ degree of crystallinity decreased further, and the sample began to melt $/ 3 /$.

\section{Nucleation}

Nucleating agents are used to form $\beta$ crystal struclure in isotactic polypropylene. Nucleating agents reported for forming $\beta$-crystal nuclei in the literature were rare earth oxides $/ 6 /$, fibers $/ 9 /$, sorbitol and benzoates $/ 10 /$, carbon black $/ 11 /, \gamma$-quinacridone $/ 7 /$. Lower hold temperatures and shorter hold times generate samples rich in $\alpha$ modification whereas longer hold times generate samples rich in $\beta$ modification during crystallization on the basis of local order /8/. Crystallization of isotactic polypropylene in its $\alpha$ modification can be initiated by low molecular weight organic materials such as benzoic acid. The (010) contace face of isotactic polypropylene interacts with nucleating agents with $0.42,0.5$ and $0.66 \mathrm{~nm}$ periodicity $/ 12 /$. Adding the nucleating agent dimethylbenzylidene sorbitol did not affect the crystallinity of biaxially oriented film $/ 13 /$.

\section{Spherulite formation}

Investigation of the effect of temperature on spherulite formation /14/ showed that decreasing cooling rate increases the spherulite diameter and the temperature gradient influences the spherulite pattern as well as the internal structure of the spherulites. 


\section{Orientation and drawing}

It is reported that the recrystallization into $\alpha$ crystals after melting of the $\beta$ phase was more suppressed at higher heating rates. Accordingly, it is preferable to heat a cast sheet rapidly to a temperature as high as possible at which the sheet does not break in the stretching process and then to stretch at this temperature. In this manner rough surfaced polypropylene appears with crater-like basins on the surfaces $17 /$. Morphology depends on the relation between the drawing ratios used in bi-directional (machine direction and transverse direction) stretching processes $/ 15 /$. It was observed that during the stretching and blowing of polypropylene bottles some orientation of (040) and (130) planes was observed along the stretch direction, the (111), (041) and (131) planes also appear oriented with intensity enhancement at about $45^{\circ}$ of azimuthal angle in X-ray transmission patterns $/ 16 /$.

There are controversial criteria for $b$-axis orientation in the literature $/ 17,18 /$. The orientation of unit cells of polypropylene can be found from the $\mathrm{X}$ ray diagram. In order to evaluate the degree of $\mathrm{b}$-axis orientation, the ratio of intensity of the (040) reflection to that of the (110) reflection was obtained. The reported value for the isotropic case was 0.54 . For talc filled oriented samples, the value was 1.19 showing b-axis orientation as reported by Gutierrcz et al. /17/.

The relationship between the orientation of the polypropylene $\mathbf{a}$ and $\mathbf{b}$ axes can also be obtained by taking the ratio of the intensity of the polypropylenc (110) plane to the (040) plane. If the ratio is less than 1.3, then the $b$ axis lies predominantly parallel to the surface under analysis. If the ratio is greater than 1.5 , then the a axis is parallel to the surface under analysis. If the ratio lies between 1.3 and 1.5 , then there is an isotropic mixture of crystallites as stated by Cook and Harper /18/. Mechanical, thermal and optical properties of biaxially oriented polypropylene films were affected by the temperature of the quenching roller and the machine direction draw ratio $/ 13 /$.

\section{Infrared analysis}

Infrared spectroscopy is a valuable means for the surface and bulk analysis of polymer films. Crystalline isotactic polypropylene has peaks at $809,842,894$, and $997 \mathrm{~cm}^{-1}$. Crystalline syndiotactic polypropylene has peaks at 866 and $997 \mathrm{~cm}^{-1}$ and amorphous syndiotactic polypropylene has 
absorbances at 1131,1199 and $1230 \mathrm{~cm}^{-1}$. Isotacticity does not change for the heated films at $130^{\circ} \mathrm{C}$ in air up to 20 days. Thermo-oxidative ketonic products absorb light at 1726 and $1718 \mathrm{~cm}^{-1} / 19 /$. Migration of antioxidants added to polypropylene may also be studied by IR spectroscopy. Spatafore and Pearson /20/ investigated the migration of phenol and phosphite based antioxidants. Phenol based antioxidants have an absorption range between 1665 and $1821 \mathrm{~cm}^{-1}$ and between 3500 and $3600 \mathrm{~cm}^{-1}$ whereas phosphite based antioxidants have an absorption range between 1057 and $1119 \mathrm{~cm}^{-1}$.

In this study it is aimed to study physical and chemical changes during casting, unidirectional and bi-directional drawing stages of biaxially oriented polypropylene films produced in the packaging industry. The films were studied by $\mathrm{X}$ ray fluorescence spectroscopy, wide angle $\mathrm{X}$ ray diffraction, differential scanning calorimetry and infrared spectroscopy.

\section{EXPERIMENTAL}

\section{Materials}

Polypropylene film from PETKIM MH 418 with a heat sealable coating was obtained by co-extrusion through $900 \mathrm{~kg} / \mathrm{h}$ and $100 \mathrm{~kg} / \mathrm{h}$ capacity extruders. The heat sealable coating contained polyethylene-polypropylene co-polymer masterbatch and an anti-static and anti-block masterbatch. Typical masterbatches used for that purpose were Eltex P KS409 and ABPP 0555TC.

\section{Processing}

The films were produced using a Mitsubishi BOPP line by quenching the melt flow from extruder by three rollers at $25-60^{\circ} \mathrm{C}$, drawing in machine direction by faster rotating rollers at $151^{\circ} \mathrm{C}$ roller temperature and hot stretching of the films in transverse direction in an oven at $174^{\circ} \mathrm{C}$ using a tenter. The film temperature in the oven was lower than the melting point of the films. The polypropylene samples studied were cast films, unidircctional stretched film with machine direction draw ratio of 7:1; and bi-directional stretched film with machine direction draw ratio of 7:1 followed by transverse direction draw ratio of 4:1. They were taken from an uncontrolled shutdown of the processing line of Polinas Packing Film Plant in Turkey. Films were cooled down to room temperature spontancously from their 
processing temperature in a very short time. Thus it can be assumed they are frozen in their process conditions. Thicknesses of the cast film, unidirectional film and BOPP film were $1.95 \mathrm{~mm}, 870 \mu \mathrm{m}$ and $20 \mu \mathrm{m}$ respectively. While the cast and unidirectionally drawn films were opaque, BOPP films were transparent.

\section{Methods}

Encrgy Dispersive X-Ray Analysis (EDX) and Scanning Electron Microscopy (SEM) data were obtained with a Philips XL-305 FEG instrument. Samples were coated with $\mathrm{Pd}-\mathrm{Au}$ by magnetron sputtering. The particles that appear on the cross section of the films as well as the continuous phases were examined by EDX. XRD data were taken with Philips X'Pert Pro instrument.

$X$-ray diffraction diagrams of both faces of the samples were obtained by using a Philips Powder X-Ray diffraction instrument. $\mathrm{CuK}_{\alpha}$ radiation with wavelength $0.154 \mathrm{~nm}$ was used. Bi-axially oriented films were placed both in transverse and machine direction in the sample holder, to see the effects in orthogonal directions.

DSC Analysis: Polypropylene samples were heated from $25-250^{\circ} \mathrm{C}$ at a rate of $10^{\circ} \mathrm{C} / \mathrm{min}$ and cooled from $250-25^{\circ} \mathrm{C}$ at a rate of $2^{\circ} \mathrm{C} / \mathrm{min}$ by using Shimadzu DSC 50 differential scanning calorimeter. The heating process was repeated for a second time under the same conditions. The areas of melting endotherms of the first and second heating were used to determine crystallinity. Crystallization energy was determined by the exothermic peak area observed during the cooling process. The heat of fusion of $209 \mathrm{~J} / \mathrm{g}$ for $100 \%$ crystalline isotactic polypropylene was used in the crystallinity calculation $/ 4 /$.

IR Analysis: Diffuse reflection spectra for both faces of cast films and films drawn in machine direction, and reflection and transmission spectra for bi-directional stretched films were taken with a Shimadzu IR-470 infrared spectrophotometer. Since the cast and unidirectional films were too thick to obtain their transmission spectra, only their diffuse reflectance spectra were obtained. 


\section{RESULTS AND DISCUSSION}

\section{Morphology and Chemical Composition of the Films}

Cross sections of polymer films were examined by Scanning Electron Microscope and their micrographs are shown in Figure 1. Cast, monoaxially drawn films and bi-axially oriented polypropylene films cross sections seen in Figure 1 indicated there were inorganic particles in the films. While the particles appear to be embedded in the polymer phase in cast and monoaxially drawn films, they distinctly appear as a different phase in the biaxially drawn film. Bi-axially oriented film in Fig 1.3 seemed to have two layers separated by a line. This line could form due to stretching the polymer phase around rigid particles.

EDX analysis was done on the polymer phase and the particle phase of the top and bottom layers at 6 different points. The representative results are shown in Figures 2 and 3 and the average chemical compositions are reported in Table 1. The polymer phase of the top layer of bi-axially oriented polypropylene had average weight percentages of $83.09,15.0,0.75$ and 1.16 of $\mathrm{C}, \mathrm{O}, \mathrm{Al}$ and $\mathrm{Ca}$ elements respectively. The polymer phase of the bottom layer of bi-axially oriented polypropylene had average weight percentages of $83.25,13.92,1.81$ and 1.01 of $\mathrm{C}, \mathrm{O}, \mathrm{Al}$ and $\mathrm{Ca}$ elements respectively. The polymer phase of the top layer contained more oxygen $(15.0 \%)$ than that of the other layer $(13.92 \%)$.

A typical EDX of particle data in the top layer indicated the weight percentages of $66.74 \% \mathrm{C}, 24.37 \% \mathrm{O}, 2.92 \% \mathrm{Na}, 0.73 \% \mathrm{Al}, 3.40 \% \mathrm{Si}$, $0.82 \% \mathrm{Cl}$ and $1.02 \% \mathrm{~K}$ (Fig 2.2). A particle of the bottom layer had 46.86, $23.83,15.57,2.42,8.20$, and 3.12 per cent of $\mathrm{C}, \mathrm{O}, \mathrm{Mg}, \mathrm{Al}, \mathrm{Si}$ and $\mathrm{Ti}$ elements respectively (Fig 3.2). As seen in Table 1 average $C$ content of the particles in the bottom and top layer were 86.74 and $80.27 \%$ indicating they were coated with a hydrocarbon, polypropylene for this case. These particles were inorganic in origin, having $\mathrm{O}, \mathrm{Mg}, \mathrm{Al}, \mathrm{Cl}$ and $\mathrm{Ca}$ and their source could be the anti-block masterbatch.

\section{Crystal structure, crystallinity and orientation}

The X-ray diffraction diagram of the bottom surface of the cast film (curve 1 in Figure 4 ) showed that it has an isotactic $\alpha$-crystal structure, since the observed diffraction peaks coincided with the data given for $\alpha$-crystal structure of isotactic polypropylene and no peaks related to $\beta$ phase and $\alpha_{2}$ 


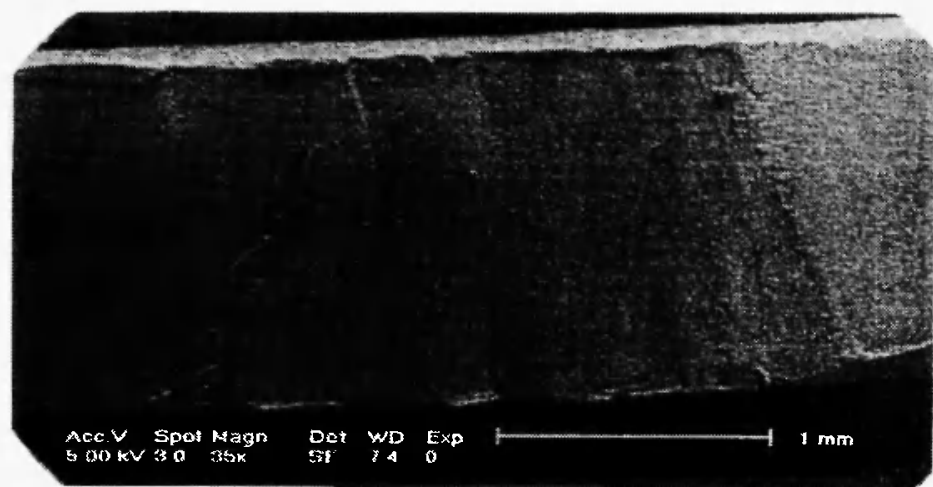

i

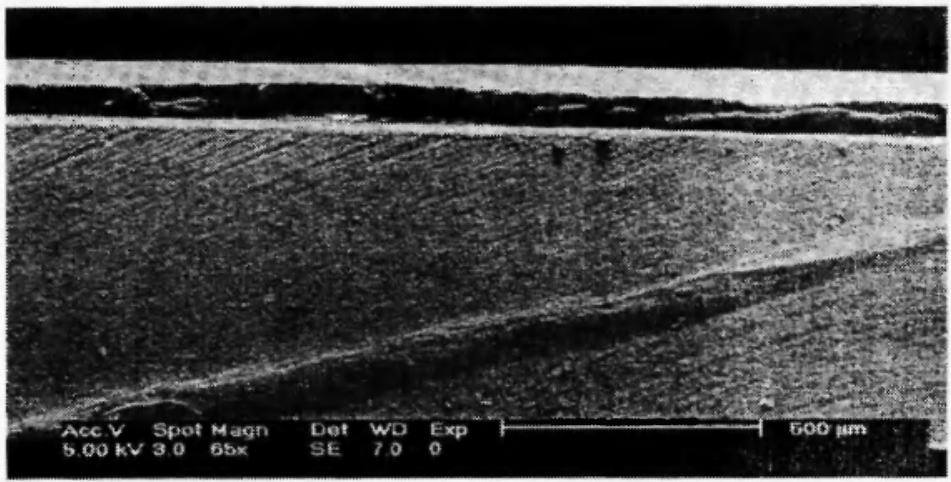

2

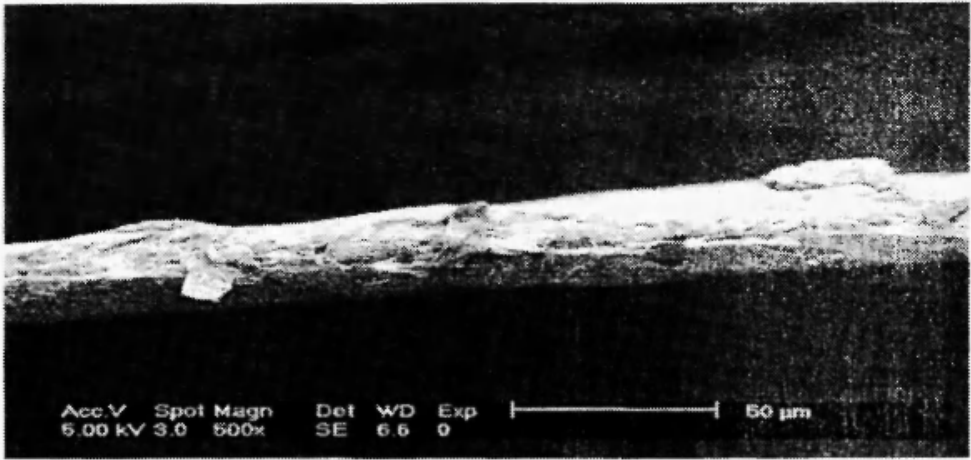

3

Fig. 1: SEM micrographs of the cross-sections of polypropylene 1. Cast lilm, 2. Uniaxially drawn film. 3. Biaxially drawn film 


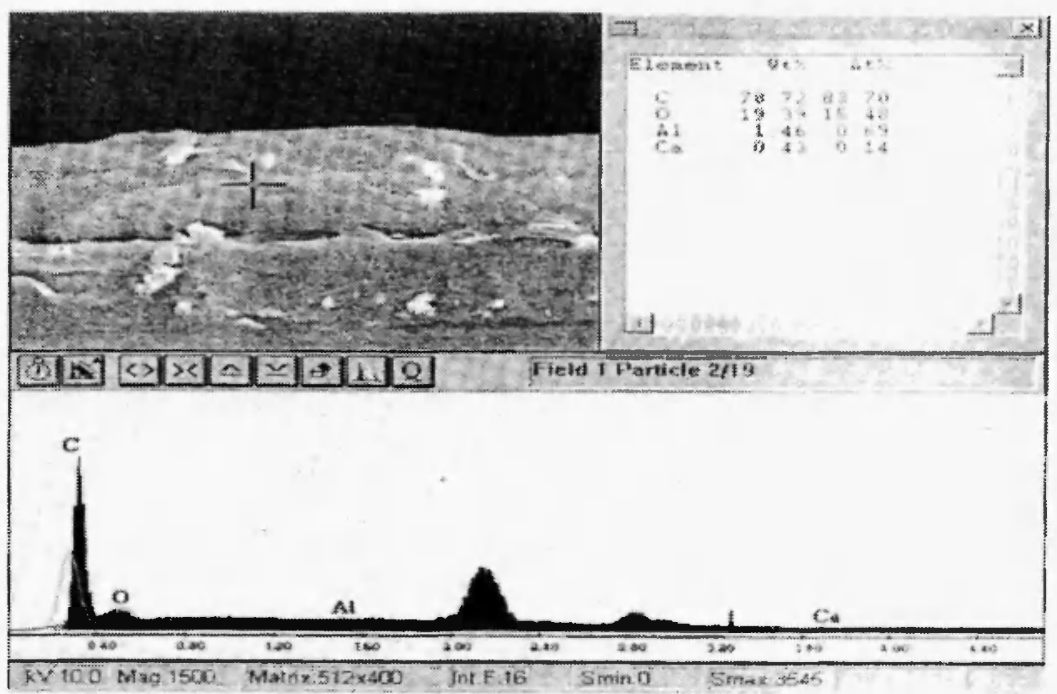

1

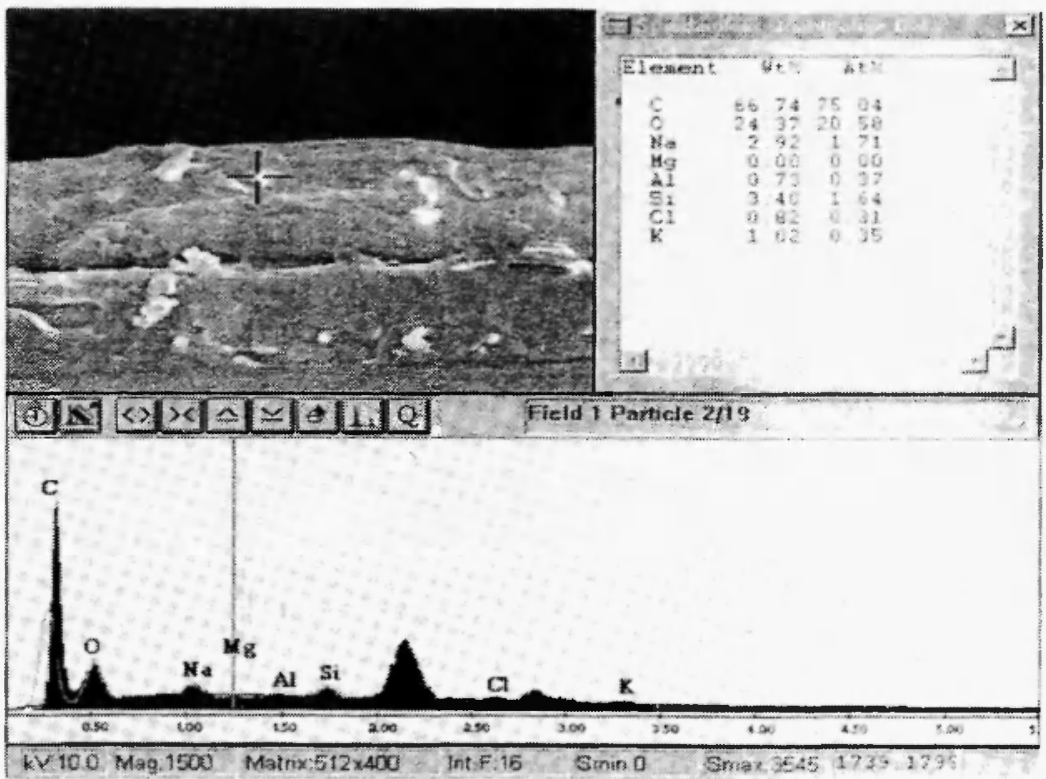

2

Fig. 2: EDX analysis of top layer of BOPP film 1. Polymer phase, 2. Particulate phase 


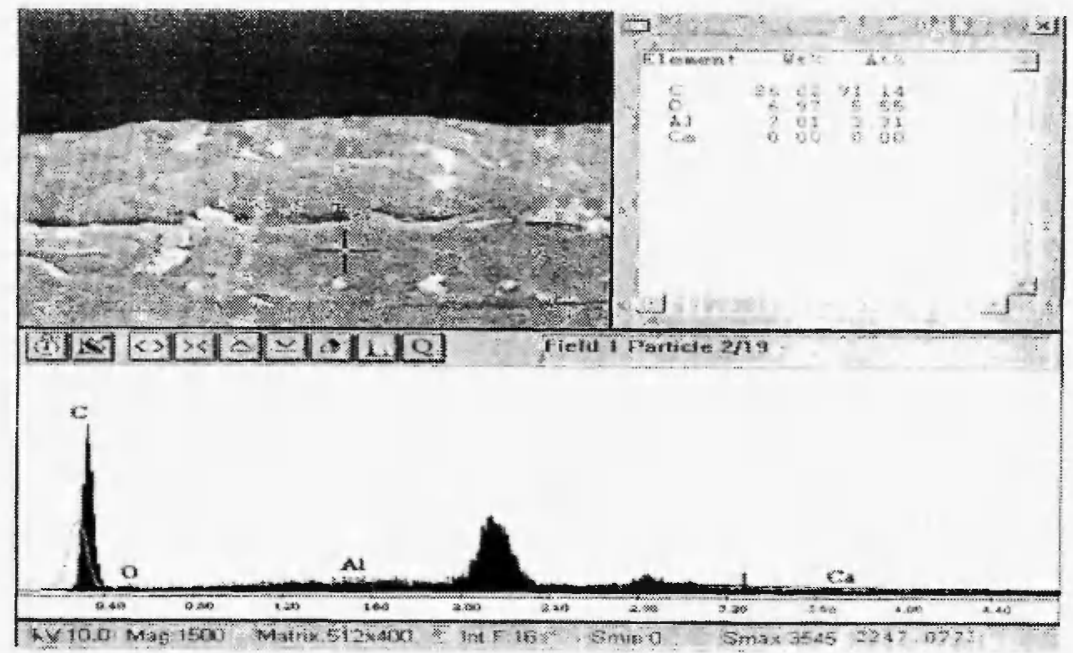

1
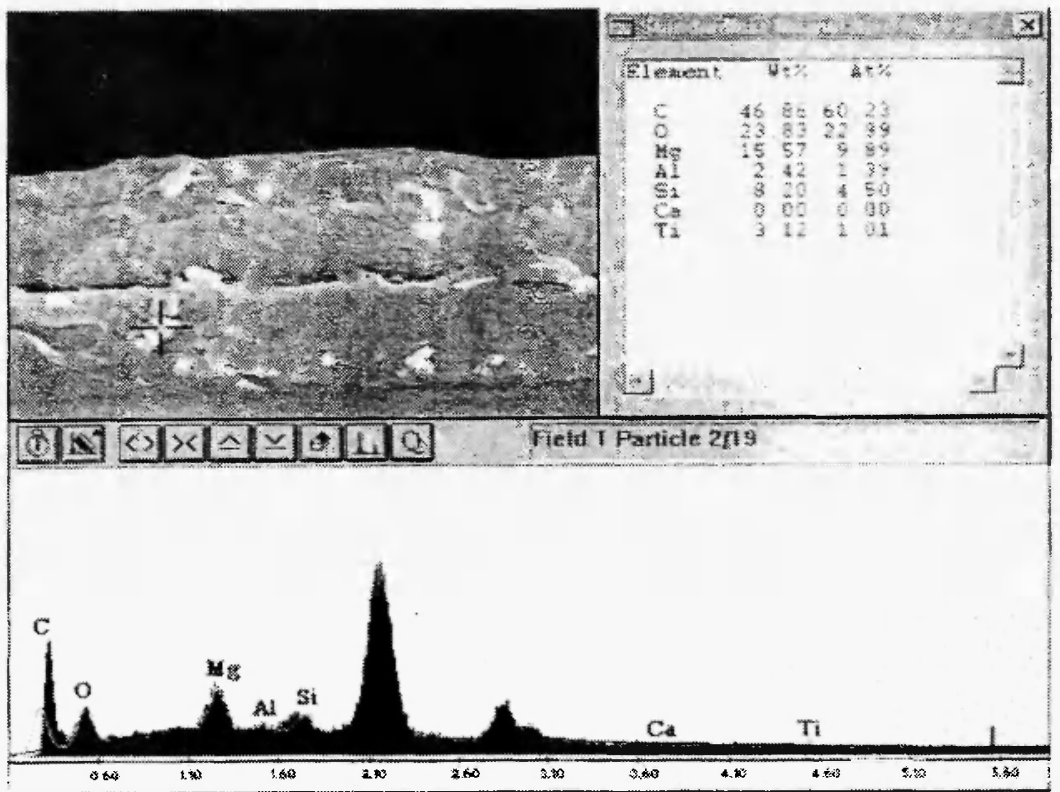

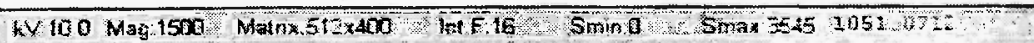

Fig. 3: EDX analysis of bottom layer of BOPP film 1. Polymer phase, 2. Particulate phase 
Table 1

The average, minimum, maximum and standard deviation of chemical compositions

\begin{tabular}{|c|c|c|c|c|c|}
\hline \multicolumn{2}{|c|}{ Elements } & Average & Minimum & Maximum & Standard \\
\hline 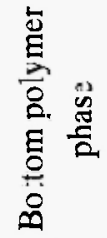 & $\begin{array}{l}\mathrm{C} \\
\mathrm{O} \\
\mathrm{Al} \\
\mathrm{Ca}\end{array}$ & $\begin{array}{c}83.25 \\
13.92 \\
1.81 \\
1.01\end{array}$ & $\begin{array}{c}77.05 \\
6.97 \\
0.43 \\
2.36\end{array}$ & $\begin{array}{c}87.46 \\
22.44 \\
7.01 \\
3.68\end{array}$ & $\begin{array}{l}3.28 \\
4.89 \\
2.38 \\
1.47\end{array}$ \\
\hline 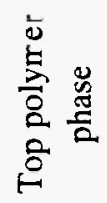 & $\begin{array}{l}\mathrm{C} \\
\mathrm{O} \\
\mathrm{Al} \\
\mathrm{Ca}\end{array}$ & $\begin{array}{c}83.09 \\
15.00 \\
0.75 \\
1.16\end{array}$ & $\begin{array}{c}78.72 \\
11.71 \\
0.46 \\
0.43\end{array}$ & $\begin{array}{c}85.93 \\
19.39 \\
1.46 \\
3.31\end{array}$ & $\begin{array}{l}3.07 \\
2.67 \\
0.48 \\
1.06\end{array}$ \\
\hline 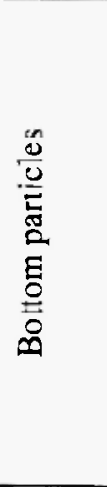 & $\begin{array}{l}\mathrm{C} \\
\mathrm{O} \\
\mathrm{Na} \\
\mathrm{Mg} \\
\mathrm{Al} \\
\mathrm{Si} \\
\mathrm{Cl} \\
\mathrm{K} \\
\mathrm{Ca} \\
\mathrm{Ti}\end{array}$ & $\begin{array}{c}70.77 \\
17.01 \\
1.48 \\
2.95 \\
0.79 \\
2.56 \\
0.77 \\
0.71 \\
1.19 \\
1.78\end{array}$ & $\begin{array}{c}46.86 \\
0 \\
0 \\
0 \\
0 \\
0 \\
0 \\
0 \\
0 \\
0\end{array}$ & $\begin{array}{c}86.74 \\
35.65 \\
2.76 \\
15.57 \\
2.42 \\
8.20 \\
3.06 \\
4.25 \\
5.09 \\
6.15\end{array}$ & $\begin{array}{c}15.49 \\
11.65 \\
1.10 \\
5.66 \\
0.99 \\
2.71 \\
1.17 \\
1.58 \\
1.90 \\
2.22\end{array}$ \\
\hline 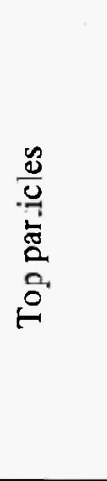 & $\begin{array}{l}\mathrm{C} \\
\mathrm{O} \\
\mathrm{Na} \\
\mathrm{Mg} \\
\mathrm{Al} \\
\mathrm{Si} \\
\mathrm{Cl} \\
\mathrm{K} \\
\mathrm{Ca} \\
\mathrm{Ti}\end{array}$ & $\begin{array}{c}75.09 \\
18.53 \\
0.82 \\
0.11 \\
0.36 \\
0.87 \\
1.55 \\
1.22 \\
0.60 \\
0.84\end{array}$ & $\begin{array}{c}66.74 \\
12.94 \\
0 \\
0 \\
0 \\
0 \\
0 \\
0 \\
0 \\
0\end{array}$ & $\begin{array}{c}80.27 \\
24.76 \\
2.92 \\
0.63 \\
1.43 \\
3.40 \\
3.99 \\
3.31 \\
2.80 \\
2.37\end{array}$ & $\begin{array}{l}4.56 \\
4.48 \\
1.04 \\
0.23 \\
0.55 \\
1.25 \\
1.73 \\
1.42 \\
1.03 \\
0.91\end{array}$ \\
\hline
\end{tabular}




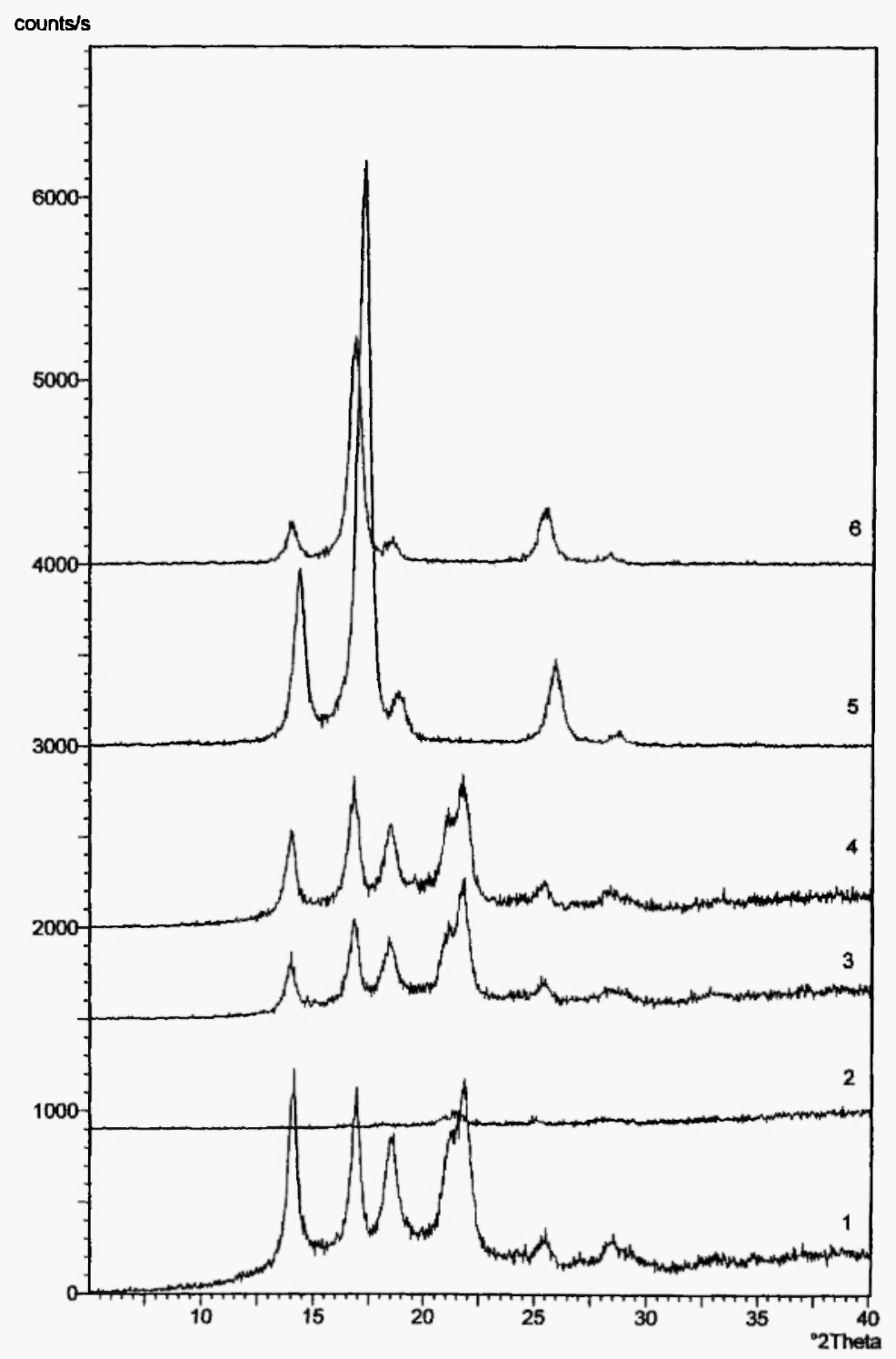

Fig. 4: X-ray diffraction curves of 1. Cast film's bottom surface, 2. Cast film's top surface, 3.Unidirectionally drawn film's bottom surface, 4 . Unidirectionally drawn film's top surface, 5. Bidirectionally stretched film's bottom surface placed in x-ray diffractometer sample holder in machine direction, 6. Bidirectionally stretched film's bottom surface placed in $\mathrm{x}$-ray diffractometer sample holder in transverse direction 
phase were present. It was observed that the cast film's top surface did not have any crystallinity, since no crystalline peaks were observed in its X-ray diffraction diagram, curve 2 in Figure 4. During melt extrusion, quenched surface by the chill roller was inverted by the other rollers of the process, forming top surface. On the other hand Figure 4, curve 3 and curve 4 showed that unidirectional drawn films had the same $\alpha$ structure at both faces. The top surface was crystallized during the orientation process. However, while the X-ray diffraction diagrams of the bottom surface of the bi-directional film in machine and transverse directions showed strong $2 \theta$ reflections of $14.2^{\prime \prime}$ and $17^{\prime \prime}$ for the (110) and (040) planes, because of the orientation, the $2 \theta$ reflection of $18.8^{\prime \prime}$ for the (130) plane and $2 \theta$ reflections of $21.2^{\prime \prime}$ and $21.9^{\prime \prime}$ for the (111), (131) and (041) planes had decreased in intensity as seen in Figure 4, curve 5 and curve 6 . These results conform with those of White and Doun /16/.

The crystallinity of the cast film's bottom surface was found to be $31 \%$ from Eq. 2 by using the data of curve 1, Figure 4. The cast film was expected to be unoriented; thus the use of Eq. 2 for the crystallinity determination was justified.

In order to evaluate the degree of b-axis orientation the ratio of intensity of the (040) reflection to that of the (110) reflection was calculated. The reported value for the isotropic case was $0.54 / 18 /$. Since higher values than 0.54 were observed, namely $0.76,1.33,1.18,3.13$, and 4 , for the cast film's bottom surface, the unidirectional film's bottom and top surfaces and bidirectional film's bottom surface in machine and transverse directions, all the films had non-isotropic crystal structure.

$\mathrm{X}$-ray diffraction analysis showed $1.3,0.75,0.84,0.32$ and 0.25 values of the ratio of intensity of 110 to 040 planes for the cast film's bottom surface, the unidirectional film's bottom surface, the unidirectional film's top surface, the bi-directional film's bottom surface in machine and transverse directions respectively. Thus the b-axis lies parallel to the surface under analysis for all samples except the cast film's bottom surface. Cast film's bottom surface was isotropic mixture of crystallites since the ratio was $1.3 / 18 /$. Thus the cast film was non isotropic according to criteria reported by Guticre' $z$ et al. /17/ and isotropic according to criteria that reported by Cook and Harper /18//

\section{Melting and crystallization}

As $\mathrm{X}$-ray diffraction showed that these films have $\alpha$-crystal structure, it is expected that an energy absorption should be observed by DSC analysis 
during the melting of this crystal structure at $10^{\circ} / \mathrm{min}$ heating rate between temperatures of $25^{\circ} \mathrm{C}$ and $250^{\circ} \mathrm{C}$. In Figure 5, heating and cooling curves of the cast film are shown. During heating, polypropylene melts and absorbs heat. However, during cooling, molten polymer crystallizes and gives off energy. Melting and crystallization are seen as endothermic and exothermic peaks in DSC curves. During re-heating of the crystallized samples, similar curves to the first one were obtained. As shown in Figure 5 and Table 2, all the films had melting peak maxima around $164-169^{\circ} \mathrm{C}$ for the first heating. The peak maxima for the second heating were lower in the range of 158 $164^{\circ} \mathrm{C}$.

In Table 2, heat of fusion, $\Delta H_{f}$, and crystallinity percentage values for the first and second heating, as well as heat of crystallization, $\Delta H_{c}$, and crystallinity percentage values for the cooling are given. The DSC crystallinity of the cast film (23\%) was fairly close to that found by $X$ ray diffraction $(31 \%)$. The first heating reflects the state of the films as developed during the fabrication processes. One-directional drawing of the film increased the crystallinity from $23 \%$ to $34 \%$, whereas bi-directional drawing

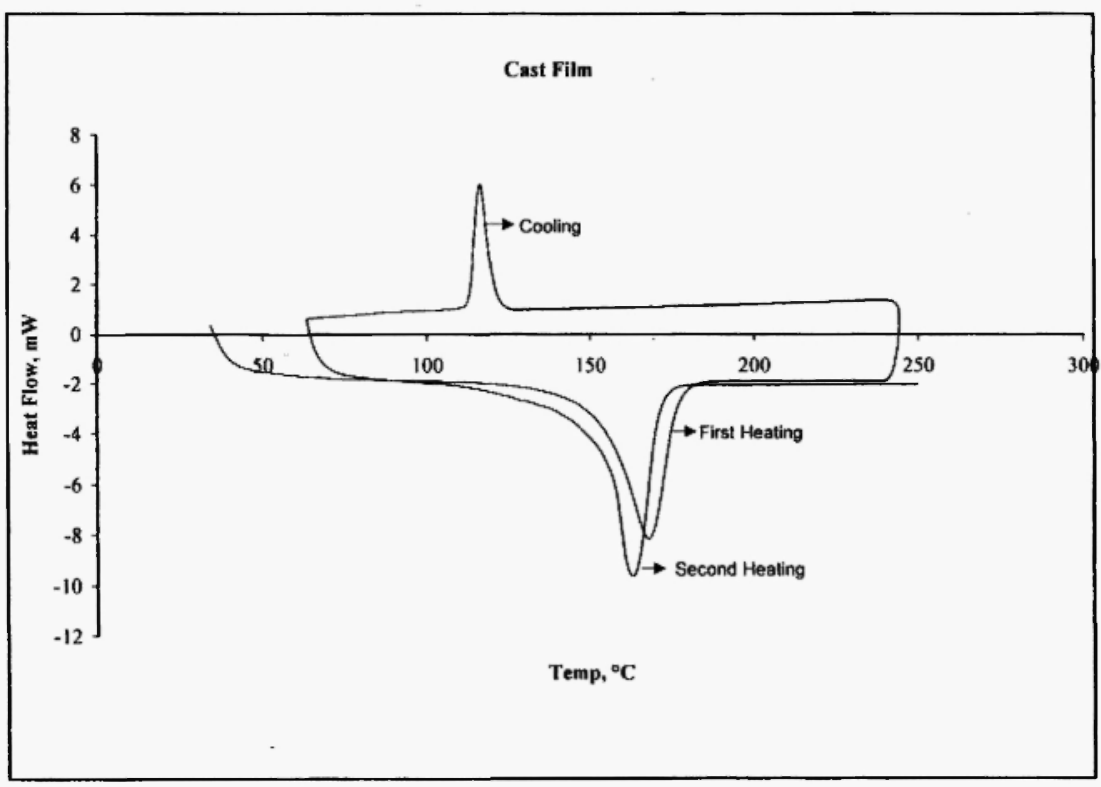

Fig. 5: Differential Scanning Calorimeter curves of Cast Film for First Heating, Cooling and Second Heating 


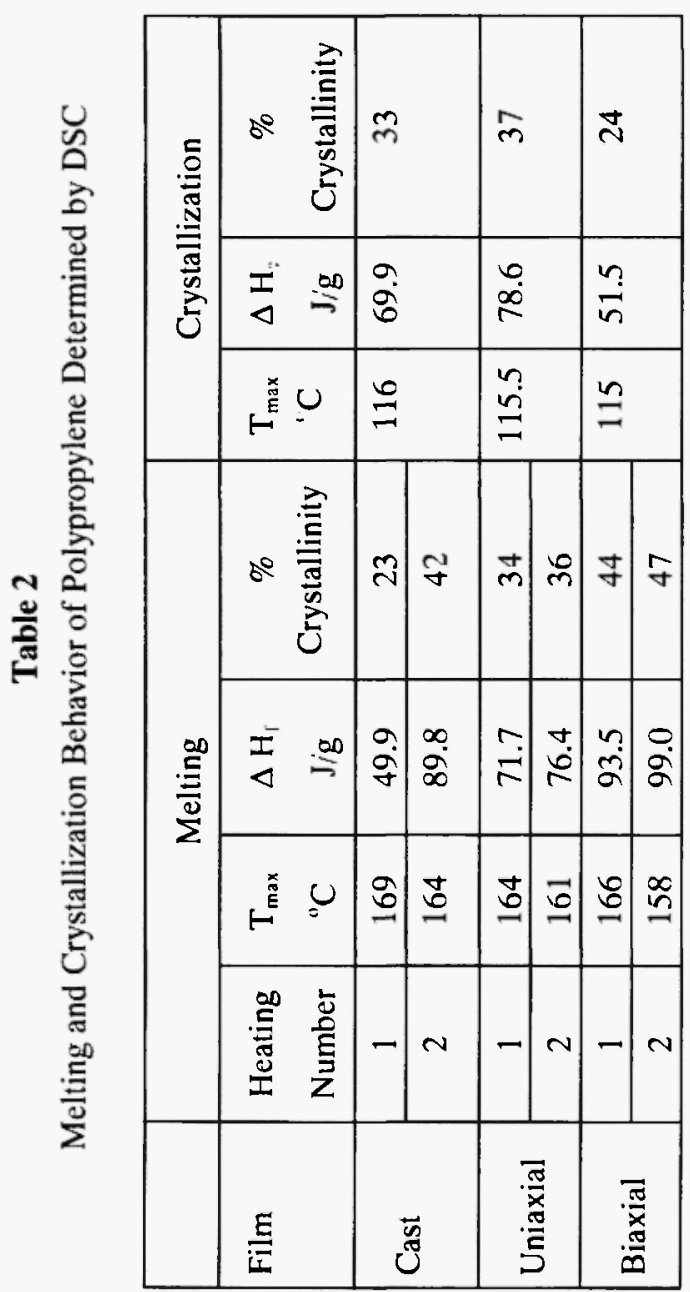


increased the crystallinity from $34 \%$ to $44 \%$. In one directional drawing of the film, there was also a thermal effect originating from hot rollers at $140^{\circ} \mathrm{C}$. Thus partial crystallization of amorphous phase by orientation occurred with the resultant effect of increased crystallinity by hot stretching. Yüksekkalaycı et al. $/ 13 /$ reported $55.2-72 \%$ crystallinity for biaxially drawn films produced at the same plant, Polinas.

For DSC tests, films were cooled with a slow cooling rate of $2^{\circ} \mathrm{C} / \mathrm{min}$ in order to attain the maximum possible level of crystallinity. For the second heating, as compared to the first heating, higher crystallinity ratios were observed for all films. As expected, all samples showed a degree of crystallinity close to each other for the second heating, since they were crystallized with the same cooling program.

\section{Infrared Spectroscopic Study of the Films}

Due to the opacity and thickness of the cast and unidirectional drawn films, they could only be studied with the diffuse reflectance technique. Although there were no details about the spectra in Figure.6, one observes a peak at $3700 \mathrm{~cm}^{-1}$, considered to be caused by a phenolic antioxidant $/ 20 \%$. Shorter peak height at $3700 \mathrm{~cm}^{-1}$ for the drawn film could be due to partial consumption of the antioxidant or due to difference in film thickness.

As shown in Figure 7, not observing this peak at both transmission and reflection spectra of thin and transparent bi-axially drawn film indicates that antioxidant was completely consumed. From Figure 7 , it is observed that bidirectional drawn films give detailed spectra. The top surface had also $\mathrm{COO}$ groups absorbing at $1540 \mathrm{~cm}^{-1}$ and $\mathrm{C}=\mathrm{O}$ groups absorbing at $1700 \mathrm{~cm}^{-1}$ (Fig. 7.2). From Figure 7, the ratio of absorbances of $998 \mathrm{~cm}^{-1}$ to $973 \mathrm{~cm}^{-1}$, $\mathrm{A}_{1,98} / \mathrm{A}_{1,73}$ was 0.97 confirming the polypropylene was isotactic $/ 19 /$. The transmission spectrum of the film indicated that $\mathrm{C}=\mathrm{O}$ and $\mathrm{COO}^{\circ}$ groups were not present in the bulk of the film.

\section{CONCLUSION}

The top surface of the films was rich in $\mathrm{C}=\mathrm{O}$ and $-\mathrm{COO}$ as indicated by IR analysis. The top polymer phase of the biaxially oriented films contained more oxygen. The adhesive properties of the top layer were increased due to oxygen-rich functional groups. Films made from polypropylene contained 


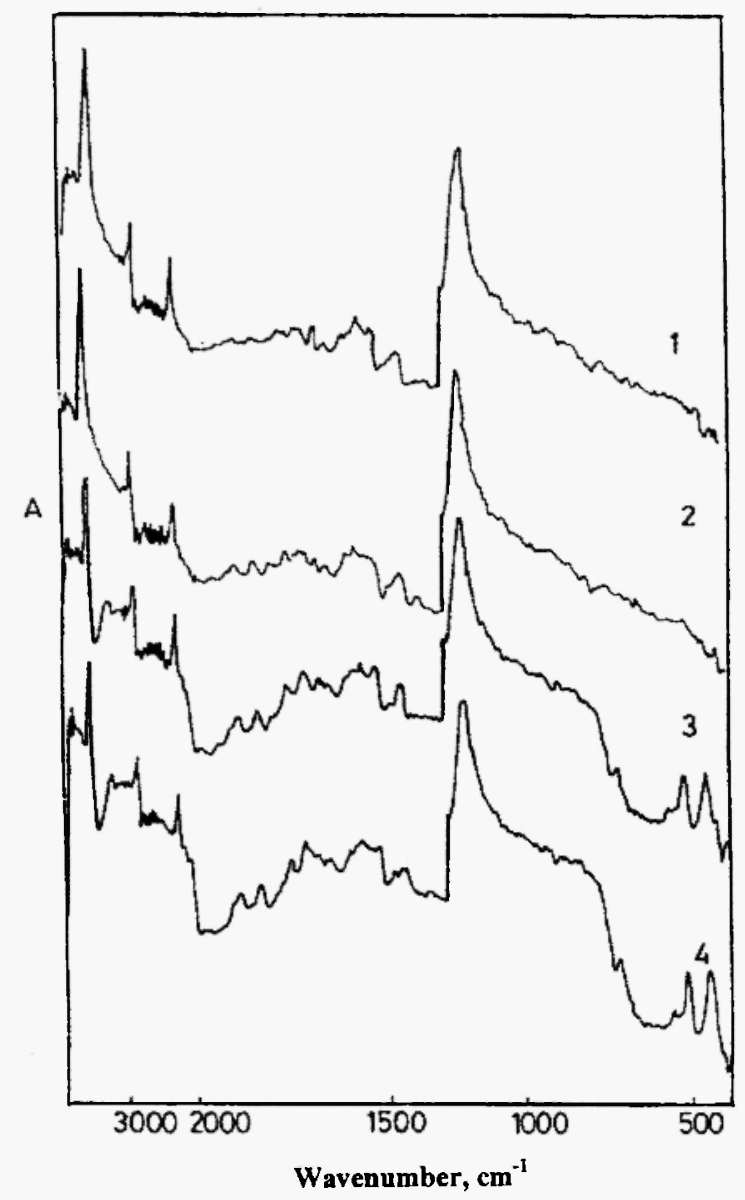

Fig. 6: Diffuse reflectance spectra of 1. Cast film's bottom surface, 2. Cast film's top surface, 3 .Unidirectionally drawn film's bottom surface, 4. Unidirectionally drawn film's top surface

particulate inorganic materials having $\mathrm{Mg}, \mathrm{Si}, \mathrm{Na}, \mathrm{K}, \mathrm{Cl}$ and $\mathrm{Ti}$ elements in trace amounts. They are added as antiblock and antislip agents to the film compound. They make the surface rough and the films do not slip on rollers in winding operation.

$\mathrm{X}$-ray diffraction showed that only isotactic $\alpha$ crystals were present in cast film. The crystallinities of the cast film determined by DSC and $\mathrm{x}$-ray diffraction was close to each other, and they were $23 \%$ and $39 \%$ respectively. 


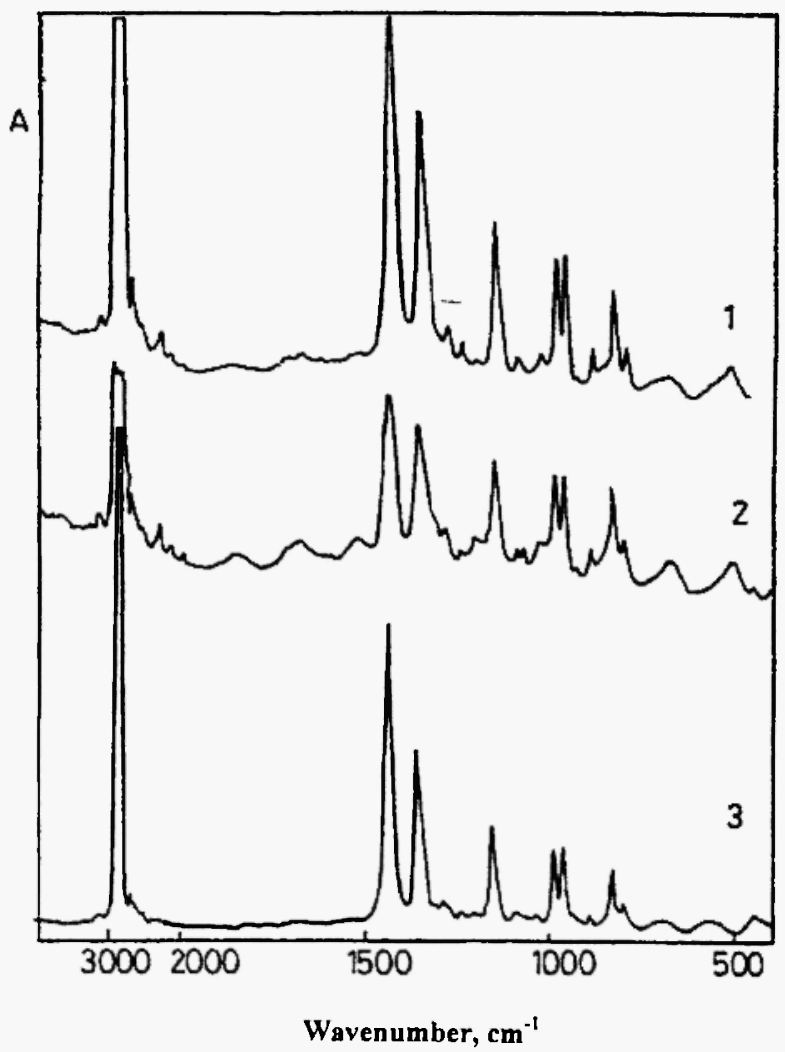

Fig. 7: Infrared spectra of bidirectionally streched film 1. reflection spectrum of the bottom surface,2. Reflection spectrum of the top surface, 3. Transmission spectrum

It was found that crystals oriented such that $b$ axis lies parallel to the film surface in machine direction and bi-axially drawn films. IR analysis showed that the phenolic antioxidant has been consumed during processing of the films preventing the oxidation of the films in hot air during processing.

Information about chemical and physical changes occurring in thin film production was obtained which can be used to control the final properties of the polypropylene films. 


\section{REFERENCES}

1. Piccarolo S, Sain M, Brucato V, Titomanlio G (1992)J Appl Polym Sci 46: 625-634.

2. Mitsuishi K, Uenos S, Kodama S, Kawasaki H (1991)J Appl Polym Sci 43:2043-2049.

3. Naiki M, Kikkawa T, Endo Y, Nozaki K, Yamamoto T, Hara T (2000) Polymer 42:5471-5477.

4. Bai F, Li F, Calhoun H, Quirk R, P, Cheng S, Z, D (1999) in: Brandrup J, Immergut EH., Grulke E (eds) Polymer Handbook, AWiley, New York, pp V/21-28.

5. Paukkeri R., Lehtinen A (1993) Polymer 34: 4075-4082.

6. Ye C, Liu J, Mo Z, Tang G, Jing X (1996) J Appl Polym Sci 60:18771881.

7. Fujiyama M, Kawamura Y, Wakino T, Okamoto T (1992) J Appl Polym Sci 36: 995-1009.

8. Cho K, Saheb DN, Choi J, Yang H (2002) Polymer 43:1407-1416.

9. Wang C., Liu CR (1999) Polymer 40: 289-298.

10. Nagarajan K, Levon K, Myerson AS (2000) J Therm Anal Cal 59: 497508.

11. Mucha M, Marszatec J, Fidrych A (2000) Polymer 41: 4137-4142.

12. Mathieu C, Thierry A, Wittman JC, Lotz B (2000) Polymer 41:72417253.

13. Yüksekkalaycı C, Yılmazer Ü, Orbey N (1999) Polym Eng Sci 39, 7: 1218-1222.

14. Pawlak A, Piorkowska E (2001) Colloid Polym Sci 279: 939-946.

15. Nie HY, Walzak MJ, McIntyre NS (2000) Polymer 41:2213-2218.

16. White SA., Doun SK (1992) Polym Eng Sci 32, 1426-1432.

17. Diez-Gutierrez S, Rodrigues-Perez MA, De Saja JA, Velasco JI (1999) Polymer 40: 5345-5353.

18. Cook M., Harper JF (1998)Adv Polym Techn 17: 53-62.

19. Horrocks AR., D'Souza JA (1991) J Appl Polym Sci 42:243-261.

20. Spatafore R., Pearson T (1991) Polym Eng Sci 31: 1610-1617. 